\title{
MicroRNA-330-3p Expression Indicates Good Prognosis and Suppresses Cell Proliferation by Targeting Bmi-1 in Osteosarcoma
}

\author{
Zhenxin Zhenga Feng Bao ${ }^{a}$ Xuhong Chen ${ }^{a}$ Hongbin Huang ${ }^{a}$ \\ Xiangfeng Zhang ${ }^{b}$ \\ aDepartment of Orthopedics, Yiwu Central Hospital, Yiwu, 'bepartment of Orthopedics, The Second \\ Affiliated Hospital Zhejiang University School of Medicine, Hangzhou, P.R. China
}

\section{Key Words}

MicroRNA-330-3p • Bmi-1 • Osteosarcoma • Tumor suppressor

\begin{abstract}
Background/Aims: Growing evidence has shown that miR-330-3p is closely related to the biological behavior of cancer, including proliferation, metastasis, and prognosis. However, there have been no reports on miR-330-3p expression and function in osteosarcoma. Methods: Expression of miR-330-3p in osteosarcoma tissues and cell lines was examined by quantitative PCR. Effects of miR-330-3p on osteosarcoma cell proliferation were investigated in vitro with the Cell Counting Kit-8 colorimetric assay. Targets of miR-330-3p were identified by dual-luciferase reporter assay. Results: The results showed that expression of miR-330 decreased in osteosarcoma tissues and cell lines. Prognosis of patients with high miR-330-3p expression was much better than that of those with low expression $(P=0.001)$, and multivariate analysis suggested that miR-330-3p is an independent prognostic factor for osteosarcoma. In addition, miR-330-3p overexpression significantly inhibited the growth of MG-63 and U2OS osteosarcoma cells. Dual-luciferase reporter assay demonstrated that Bmi-1 was a direct target gene of miR-330-3p, and in a recovery experiment, miR-330-3p suppressed osteosarcoma cell proliferation by directly targeting Bmi-1. Conclusion: Our results suggest that miR-330-3p acts as a tumor suppressor by regulating Bmi-1 expression in osteosarcoma. Thus, miR-330$3 p$ may represent a novel therapeutic target for the treatment of osteosarcoma.
\end{abstract}

\section{Introduction}

Osteosarcoma is the most common primary malignant bone tumor, and is most commonly seen in the distal femur and metaphysis of the upper tibia [1]. The degree of 


\section{Cellular Physiology Cell Physiol Biochem 2018;46:442-450 \begin{tabular}{l|l} 
DOI: 10.1159/000488612 & $\begin{array}{l}\text { O } 2018 \text { The Author(s). Published by S. Karger AG, Basel } \\
\text { www.karger.com/cpb }\end{array}$
\end{tabular} \\ Zheng et al.: MiR-330-3p Suppresses Cell Proliferation in Osteosarcoma}

malignancy in osteosarcoma is very high, and approximately $80-90 \%$ of patients present with metastasis [1]. Most osteosarcomas metastasize to the lungs, with a few spreading to the brain, prostate, kidney, and other organs [1]. Prior to the 1970s, osteosarcoma was mainly treated with amputation, but the 5-year survival rate was only $15-20 \%[2,3]$. With the advent of neoadjuvant chemotherapy, current 5-year survival rates exceed $60 \%$ [4]. However, osteosarcoma is resistant to conventional chemotherapy drugs, and its resistance increases over time. Relapse remains an important factor that leads to the failure of surgical treatment and effects the efficacy of chemotherapy [4]. Therefore, a comprehensive understanding of the etiology, carcinogenesis, proliferation, metastasis, and drug resistance of osteosarcoma is significant to improve the survival and prognosis of this disease.

MicroRNAs (miRNAs) are small molecular non-coding RNAs that are 18-25 nucleotides in length [5]. Mature miRNA mainly degrades or inhibits the transcription of mRNA or translation of proteins by binding to the $3^{\prime}$ untranslated region ( $3^{\prime}$-UTR) of target genes to regulate many aspects of cell function including regulation of the cell cycle, proliferation, apoptosis, differentiation, and cell stress [5]. In humans, encoding miRNAs only account for approximately $3 \%$ of genes but they regulate the expression of approximately $30 \%$ of proteins [5]. In recent years, many studies have shown that miRNA expression is dysregulated in many tumors, and these abnormally expressed miRNAs regulate the progression of tumors by regulating various tumor suppressor genes or oncogenes [6]. A recent study found that abnormal expression of miRNAs is closely related to biological behavior of osteosarcoma such as proliferation, metastasis, and prognosis [7]. miR-330-3p is a miRNA that has been frequently described in the literature [8-13]. However, to date, there have been no reports on its expression and role in osteosarcoma.

In this study, we examined the expression of miR-330-3p in osteosarcoma cells and tissues to determine the expression characteristics of miR-330-3p in osteosarcoma. In addition, we investigated the effects of miR-330-3p on the biological function of osteosarcoma cells. Finally, we explored the molecular mechanisms underlying miR-330-3p regulation of BMI-1 and its downstream target, to provide a new theoretical basis for further understanding the role of miR-330-3p in the development and progression of osteosarcoma.

\section{Materials and Methods}

\section{Patients and tumor tissues}

A total of 55 osteosarcoma tumor tissues and adjacent normal tissues were surgically collected from osteosarcoma patients at The Second Affiliated Hospital Zhejiang University (Zhejiang Sheng, China) between November 2007 and November 2010. Both tumor and non-tumor samples were subjected to pathological examination. Patient characteristics are summarized in Table 1. This study was approved by the Yiwu Central Hospital in accordance with the tenets of the Declaration of Helsinki. Written informed consent was obtained from all participants. All specimens were surgically removed and rapidly frozen by immersion in liquid nitrogen for subsequent experiments.

\section{Cell culture and transfection}

Osteosarcoma cell lines MG-63, U2OS, Saos-2, and HOS and the normal osteoblast cell line OB3 were purchased from American Type Culture Collection (Manassas, VA). An miR-330-3p mimic and miRNA negative control (miR-NC) were designed and synthesized by GenePharma (Shanghai, China). For transfection, $3 \times 10^{5}$ cells (MG-63 and U2OS) were plated in 6-well plates (5 $\times 10^{5}$ cells/well) and were transiently transfected with $100 \mathrm{nM}$ miR-330-3p mimic or miR-NC using siPORT neoFX Transfection Agent (Ambion Inc., Austin, TX) according to the manufacturer's protocol.

\section{miRNA extraction and quantitative PCR}

Total RNA for miRNA and mRNA analyses was isolated from tissues or cells using TRIzol reagent (Invitrogen Corp., Carlsbad, CA) according to the manufacturer's instructions. The expression of miR-330-3p and Bmi-1 was determined using the SYBR Green PCR Master Mix (Applied Biosystems Inc., Waltham, MA) and qPCR. GAPDH and U6 were used as internal controls.

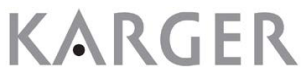




\section{Cellular Physiology Cell Physiol Biochem 2018;46:442-450 \begin{tabular}{l|l} 
and Biochemistry Published online: April 03, 2018 & $\begin{array}{l}\text { (c) } 2018 \text { The Author(s). Published by S. Karger AG, Basel } \\
\text { www.karger.com/cpb }\end{array}$ \\
\hline
\end{tabular} \\ Zheng et al.: MiR-330-3p Suppresses Cell Proliferation in Osteosarcoma}

Western blotting

Total protein was isolated from cells and tissues, and protein concentrations were determined using the BCA Protein Assay Kit (Pierce; Thermo Fisher Scientific Inc., Waltham, MA). Proteins were resolved on $12 \%$ sodium dodecyl sulfate polyacrylamide gel electrophoresis gels and transferred to polyvinylidene difluoride membranes (BioRad Laboratories, Hercules, CA). Membranes were incubated with primary antibodies against Bmi1 (1:500; Cell Signaling Technology Inc., Sunnyvale, CA) and GAPDH (1:2000; Santa Cruz Biotechnology Inc., Santa Cruz, CA) overnight at $4^{\circ} \mathrm{C}$. After extensive washing with phosphate-buffered saline containing $0.1 \%$ Triton $\mathrm{X}-100$, the membranes were incubated with horse radish peroxidase-conjugated goat anti-rabbit antibody for $30 \mathrm{~min}$ at room temperature. The bands were visualized using the ECL system (Millipore Corp., Billerica, MA).

\section{Plasmid construction and luciferase reporter assay}

The expression vector for the miR-330-3p precursor sequence was generated by cloning the PCR product into the pCDH plasmid using the following primers: 5'-CGGCAAAGCACACGGCCT-3' (forward) and 5'-TGCGTGTCGTGGAGTCGGC-3' (reverse). The antisense miR-330-3p oligonucleotide (anti-hsa-miR-330$3 p$ ) and antisense miRNA control were purchased from Qiagen Inc. (Valencia, CA). Bmi-1 3'-UTR containing the predicted miR-330-3p binding sites (both wild-type and mutant) was cloned into the psiCHECK-2 plasmid. For the luciferase reporter assay, MG-63 cells were transfected with different combinations of miR-330-3p, miR-NC, psiCHECK-2-Bmi-1 3'-UTR-WT, and psiCHECK-2-Bmi-1 3'-UTR-Mut for 24 h. Relative luciferase activities were evaluated $48 \mathrm{~h}$ later using the Dual-Luciferase Reporter Assay Kit (Promega Corp., Madison, WI).

\section{Cell proliferation}

After $24 \mathrm{~h}$ of transfection, cells were harvested and seeded into 96 -well plates at a density of $5 \times 10^{3}$ cells per well and were cultured with $5 \% \mathrm{CO}_{2}$ at $37^{\circ} \mathrm{C}$ for $1,2,3$, or 4 days. A total of $10 \mu \mathrm{L}$ Cell Counting Kit8 solution (Dojindo Laboratories, Kumamoto, Japan) was added to the culture medium in each well. After incubation for $1 \mathrm{~h}$, the optical density values were read using a microplate reader (Bio-Tek Co., Winooski, VT) at $450 \mathrm{~nm}$. Measurements at each time point were repeated in the three wells, and the experiment was independently performed in triplicate. Briefly, cells were seeded in the chambers with medium containing $0.1 \%$ fetal bovine serum (FBS), whereas medium containing 20\% FBS was placed in the lower chambers. After $24 \mathrm{~h}$, cells that invaded the Matrigel were fixed in 4\% paraformaldehyde and stained with crystal violet. The number of invaded cells was counted in five randomly selected microscopic fields and photographed. 


\section{Cellular Physiology Cell Physiol Biochem 2018;46:442-450 \begin{tabular}{ll|l} 
DOI: 10.1159/000488612 & $\begin{array}{l}\text { O } 2018 \text { The Author(s). Published by S. Karger AG, Basel } \\
\text { www.karger.com/cpb }\end{array}$ \\
\hline and Biochemistry
\end{tabular}

\section{Statistical analysis}

Correlation between miR-330-3p expression and clinicopathological features was determined by the $\chi^{2}$ test. Survival curves were analyzed using the Kaplan-Meier method, and the statistical effect was evaluated using the log-rank test. Additionally, the Cox regression model was employed to determine if miR-330-3p is an independent prognostic factor of osteosarcoma. The two-tailed unpaired Student's $t$-test was adopted to compare the difference in expression among the different groups. Statistical analysis was conducted using Graphpad Prism (version 6.01; La Jolla, CA) and SPSS 21.0 software (IBM Statistics, Chicago, IL). P values less than 0.05 were considered statistically significant unless otherwise specified.

\section{Results}

Expression of miR-330 was decreased in osteosarcoma tissues and cells

qPCR was used to investigate expression of miR-330-3p in 55 osteosarcoma tissues and paracancerous tissues. Relative expression of miR-330-3p in tumor tissues normalized to U6 was $1.97 \pm 0.24$ (mean \pm standard deviation), whereas relative expression of miR-330-3p in adjacent normal tissues was $4.36 \pm 0.27$. Among the 55 patients, 43 had lower miR-330-3p expression in tumor tissues than in adjacent tissues $(\mathrm{P}<0.001$; Fig. $1 \mathrm{~A})$. In addition, miR-330$3 \mathrm{p}$ expression in the osteosarcoma cell lines was significantly lower than that in the normal osteoblastic cell line (Fig. 1B).

The prognostic value of miR-330-3p in osteosarcoma

Patients with osteosarcoma were divided into two groups based on the median miR330-3p expression. As shown in Table 1, the expression of miR-330-3p was unrelated to sex, age, histological grade, histological type, tumor size, or tumor stage. However, the prognosis of patients with high miR-330-3p expression was much better than that of patients with low expression ( $\mathrm{P}=0.001$; Fig. $1 \mathrm{C}$ ). In univariate analysis, age $\geq 20$ years, undifferentiated type, stage III, and low miR-330-3p expression were factors that contributed to the poor prognosis of patients with osteosarcoma $(\mathrm{P}<0.05$; Table 2). In Cox regression multivariate analysis, tumor stage and miR-330-3p expression were independent prognostic factors (Table 2).

miR-330-3p suppressed osteosarcoma cell proliferation

To study the functions of miR-330-3p in osteosarcoma cells, we overexpressed miR-3303p in MG-63 and U2OS cells (Fig. 2A, B), which significantly inhibited cell growth (Fig. 2C, D).

Fig. 1. (A) Expression of miR$330-3 p$ in 55 paired osteosarcoma samples and their corresponding normal tissues detected by qPCR; (B) $\mathrm{miR}-330-3 \mathrm{p}$ expression in the human osteosarcoma cell lines MG63, U20S, Saos-2, and HOS, and the normal osteoblastic cell line OB3 detected by qPCR; (C) Kaplan-Meier curve for osteosarcoma patients classified with high or low miR-3303 p expression; P-value was calculated using the log-rank test.

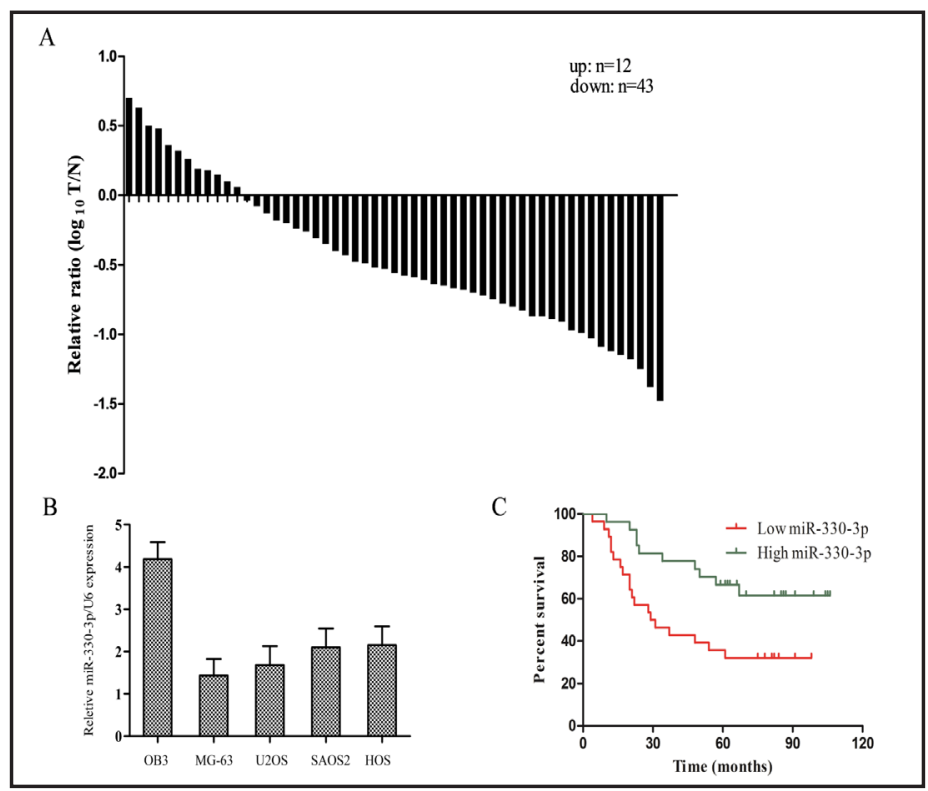


Table 2. Univariate and multivariate Cox regression analyses for overall survival in patients with osteosarcoma

\begin{tabular}{|c|c|c|c|c|}
\hline \multirow{2}{*}{ Variables } & \multicolumn{2}{|c|}{ Univariate analysis } & \multicolumn{2}{|c|}{ Multivariate analysis } \\
\hline & HR $(95 \% \mathrm{CI})$ & $P$ value & HR $(95 \% \mathrm{CI})$ & P value \\
\hline \multicolumn{5}{|l|}{ Sex } \\
\hline Male vs. Female & $2.03(0.94-4.37)$ & 0.072 & & \\
\hline \multicolumn{5}{|l|}{ Age } \\
\hline$\geq 20$ years vs. $<20$ years & $1.47(1.07-2.03)$ & $0.019^{*}$ & $1.21(0.83-1.77)$ & 0.329 \\
\hline \multicolumn{5}{|l|}{ Histological grade } \\
\hline $\begin{array}{l}\text { Undifferentiated vs. } \\
\text { differentiated }\end{array}$ & $1.40(1.06-1.84)$ & $0.016^{*}$ & & \\
\hline \multicolumn{5}{|l|}{ Histological type } \\
\hline Osteoblastic vs. other & $2.06(0.91-4.66)$ & 0.082 & $1.22(0.90-1.68)$ & 0.215 \\
\hline \multicolumn{5}{|l|}{ Tumor size } \\
\hline$>8 \mathrm{~cm}$ vs. $\leq 8 \mathrm{~cm}$ & $1.29(0.57-2.92)$ & 0.536 & & \\
\hline \multicolumn{5}{|l|}{ Tumor stage } \\
\hline III vs. I+II & $2.56(1.16-5.65)$ & $0.020^{*}$ & $2.33(1.06-5.13)$ & $0.036^{*}$ \\
\hline \multicolumn{5}{|l|}{ miR-330-3p } \\
\hline Low vs. High & $2.64(1.22-5.69)$ & $0.014^{*}$ & $2.28(1.04-4.99)$ & $0.039^{*}$ \\
\hline
\end{tabular}

Fig. 2. (A) MG-63 and U20S cells transfected with hsa-miR-330-3p mimic or negative control (NC). Expression of miR330-3p confirmed by qPCR in both MG-63 and U20S cell lines. Overexpression of miR-330-3p inhibited (B) MG-63 and (C) U2OS proliferation. Cell proliferation measured by the CCK-8 assay at the indicated times.
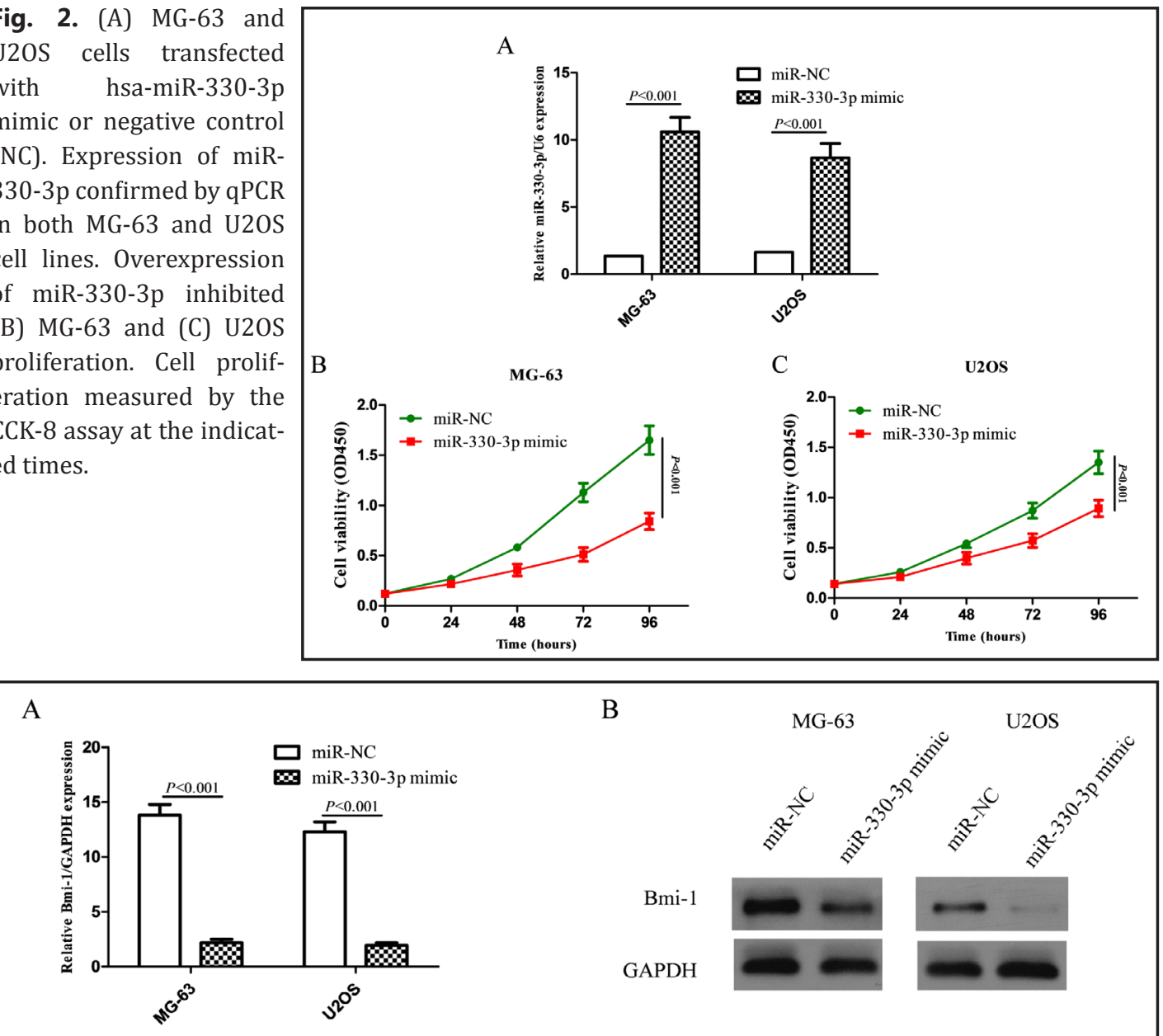

B

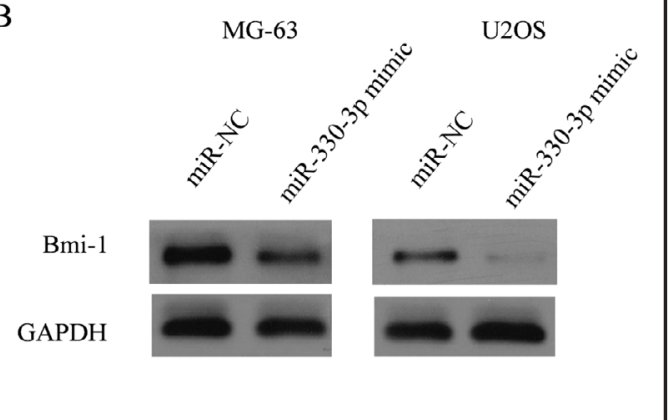

Fig. 3. mRNA levels of Bmi-1 in (A) MG-63 and U2OS cells examined by qPCR after transfection with miR330-3p mimic or NC. Protein levels of Bmi-1 in (B) MG-63 and U2OS cells examined by western blotting after transfection with miR-330-3p mimic or NC. 


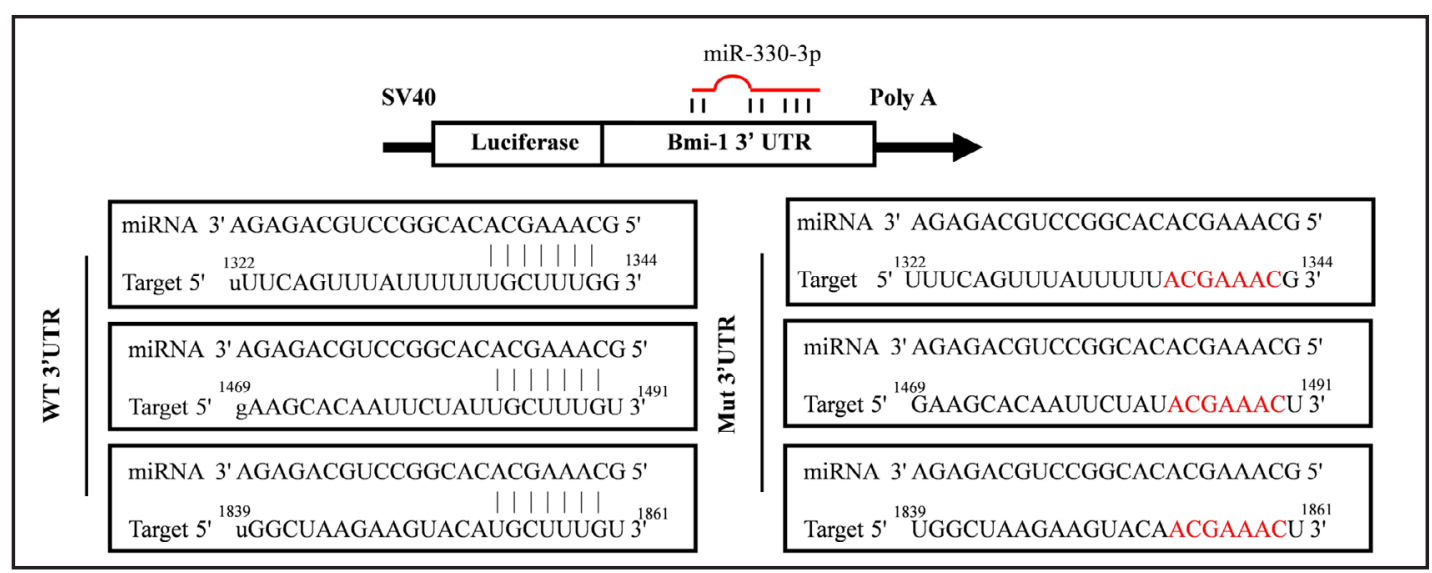

Fig. 4. Construction of the psiCheck2 reporter plasmid containing wild-type or mutant Bmi-1 3'-UTR.

We also evaluated the influence of miR-330-3p on the invasive ability of osteosarcoma cells and found that the overexpression of miR330-3p did not inhibit the invasion ability of U20S and MG-63. These data suggest that the main function of miR-330-3p is to inhibit the proliferation, rather than the invasion ability, of osteosarcoma cells.

miR-330-3p suppressed osteosarcoma cell proliferation by directly targeting Bmi-1

To investigate how miR-330-3p regulates the proliferation of osteosarcoma cells, we used TargetScan and miRBase databases to identify target genes to which miR-330-3p might bind. In screening candidate genes, we found that Bmi- 1 bound to the $3^{\prime}$ UTR region of miR-330-3p. To determine if miR-330-3p regulates $B m i-1$, the effects of the miR-330$3 \mathrm{p}$ mimic or miR-NC on the mRNA and protein expression levels of Bmi-1 in osteosarcoma cells were examined. The results showed that

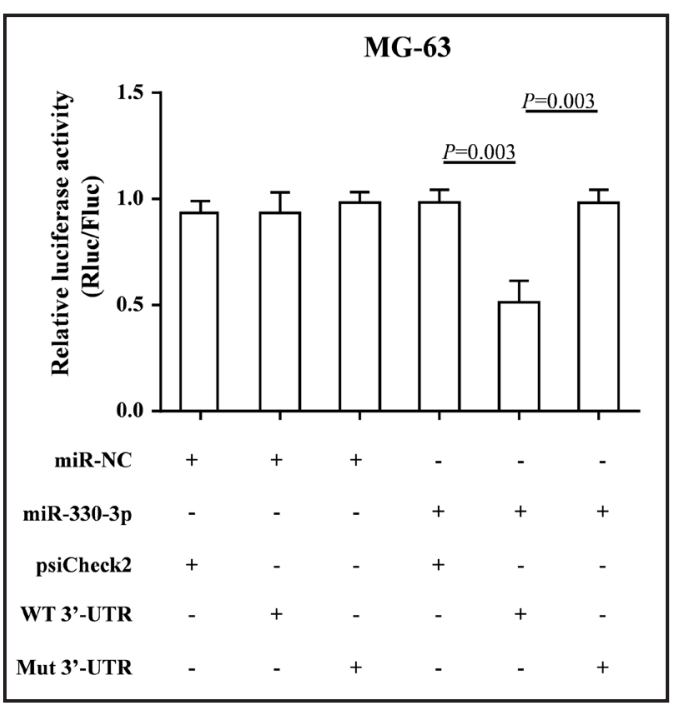

Fig. 5. Luciferase assay of MG-63 cells transfected with Bmi-1 3'UTR luciferase vectors, miR-330$3 p$, or miR-NC control. Luciferase activity was measured $24 \mathrm{~h}$ after transfection. overexpression of miR-330-3p in MG-63 and U20S cells significantly decreased Bmi-1 mRNA and protein expression (Fig. 3). To determine if miR-330-3p directly regulates Bmi-1, we cloned wild-type and mutant $3^{\prime}$-UTR (the miR$330-3 p$ binding site was mutated) of Bmi-1 into the psiCheck-2 luciferase reporter vector (Fig. 4), and performed luciferase assays in MG-63 cells. The results showed that miR-3303 p directly inhibited the luciferase reporter activity of wild-type $3^{\prime}$-UTR but not of mutated Bmi-1 3'-UTR (Fig. 5). Together, these results demonstrate that Bmi-1 is a direct target gene of miR-330-3p. To evaluate if miR-330-3p regulates the proliferation of cells by Bmi-1, we transfected miR-330-3p alone, Bmi-1 overexpression plasmid (not containing 3'-UTR), or both in osteosarcoma cells and then observed their proliferation ability. Osteosarcoma cells transfected with miR-330-3p grew significantly slower than control cells, whereas Bmi-1-transfected cells grew faster than control cells (Fig. 6). Interestingly, co-transfection of Bmi-1 with miR-330-3p completely reversed the decreased proliferation of MG-63 and U20S cells induced by miR-330-3p (Fig. 6). These data showed that miR-330-3p suppressed osteosarcoma cell proliferation by directly targeting Bmi-1. 


\section{Discussion}

Has-miR-330 is located on the human chromosome 19q13.32 [9]. miR-330-5p/3p is processed by the 5' and 3' end arms of the miR-330 precursor, respectively. Although 5p and $3 p$ come from the same hairpin structure, their seed sequences are different, so their functions and target mRNAs may also differ. In general, both miR-330-5p/3p exist, but at different expression levels. Due to the low expression of miR-330-5p, this study focused on miR-330-3p. Previous studies have shown that miR-330-3p is abnormally expressed in various tumors and is upregulated in breast [13], liver [14], esophageal [11], and lung cancers [15] and glioma [16, 17]. Mesci et al. [13] found that miR-330-3p is highly expressed in breast cancer tissues and promotes the metastasis of breast cancer cells through the targeted regulation of CCBE1. Hu et al. [14] found that the high expression of miR-330-3p and its regulation of CCBE1 in hepatocellular carcinoma (HCC) promote the proliferation and invasion of HCC cells through the targeted regulation of inhibitor of growth protein 4. Meng et al. [11] suggested that miR-330-3p promotes the proliferation and invasion of esophageal squamous cell carcinoma cells by inhibiting the expression of programmed cell death protein 4 . Liu et al. [15] demonstrated that miR-330-3p is highly expressed in lung cancer tissues, and that its overexpression promotes the proliferation of non-small cancer lung cells by targeted inhibition of extracellular growth factor 2. Yao et al. [17] found that miR-330-3p promotes the proliferation, migration, and apoptosis of glioma cells by regulating SH3GL2 expression. However, some studies have reported that the expression of miR-330-3p is downregulated in many tumors including gastric [12], colon [18] and prostate cancers [9, 19]. Lee et al. [9] noted that the expression of miR-330-3p in prostate cancer tissues is downregulated, inducing apoptosis of PC-3 prostate cancer cells. Guan et al. [12] found that the expression of miR-330-3p is downregulated in gastric cancer tissues and inhibits the proliferation of gastric cancer cells by regulating MSI1. Similar findings were found in a study of colorectal cancer conducted by Li [18]. Together, these studies suggest that miR-330-3p may have functions similar to protooncogenes and tumor suppressor genes.

To determine how miR-330-3p acts as a tumor suppressor, we screened the target genes of miR-330-3p using bioinformatics analysis. Bmi-1 was selected as a potential target gene of miR-330-3p based on its functions and expression patterns. It has not been previously reported that miR-330-3p can directly target Bmi-1 in tumors, but it is known to play an important role in the proliferation and invasion of various tumors [20]. In addition, Bmi-1 controls the self-renewal, proliferation, and cell cycle of tumor stem cells by regulating the p16Ink4a/Rb and/or p14ARF/MDM2/p53 tumor suppressor pathways [21, 22]. 


\section{Cellular Physiology Cell Physiol Biochem 2018:46:442-450

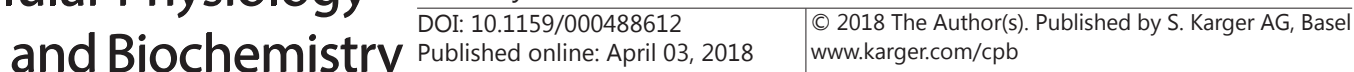 \\ Zheng et al.: MiR-330-3p Suppresses Cell Proliferation in Osteosarcoma}

\section{Conclusion}

In summary, we confirmed that miR-330-3p expression in osteosarcoma was significantly lower than that in normal tissue, and was closely correlated with tumor size. Upon further analysis of the relationship between miR-330-3p and overall survival, we found that overall survival was significantly lower in the group with low miR-330-3p expression was than in the group with high expression. Multivariate analysis showed that miR-330-3p was an independent prognostic factor in patients with osteosarcoma. In addition, miR-330-3p inhibited the growth of osteosarcoma cells. The luciferase reporter assay demonstrated that Bmi-1 is a novel target gene for miR-330-3p and reversed the inhibitory effects of miR-330$3 p$ in osteosarcoma cells. Therefore, miR-330-3p may represent a novel therapeutic target for osteosarcoma treatment.

\section{Disclosure Statement}

No conflict of interest exists.

\section{References}

1 Mirabello L, Troisi RJ, Savage SA: Osteosarcoma incidence and survival rates from 1973 to 2004: Data from the surveillance, epidemiology, and end results program. Cancer 2009;115:1531-1543.

-2 Geller DS, Gorlick R: Osteosarcoma: A review of diagnosis, management, and treatment strategies. Clin Adv Hematol Oncol 2010;8:705-718.

3 Gelderblom H, Jinks RC, Sydes M, Bramwell VH, van Glabbeke M, Grimer RJ, Hogendoorn PC, McTiernan A, Lewis IJ, Nooij MA, Taminiau AH, Whelan J: Survival after recurrent osteosarcoma: Data from 3 european osteosarcoma intergroup (eoi) randomized controlled trials. Eur J Cancer 2011;47:895-902.

-4 Luetke A, Meyers PA, Lewis I, Juergens H: Osteosarcoma treatment - where do we stand? A state of the art review. Cancer Treat Rev 2014;40:523-532.

5 Bartel DP: Micrornas: Genomics, biogenesis, mechanism, and function. Cell 2004;116:281-297.

6 Di Leva G, Croce CM: Mirna profiling of cancer. Curr Opin Genet Dev 2013;23:3-11.

7 Kushlinskii NE, Fridman MV, Braga EA: Molecular mechanisms and micrornas in osteosarcoma pathogenesis. Biochemistry (Mosc) 2016;81:315-328.

8 Jiang LP, Zhu ZT, Zhang Y, He CY: Downregulation of microrna-330 correlates with the radiation sensitivity and prognosis of patients with brain metastasis from lung cancer. Cell Physiol Biochem 2017;42:22202229.

-9 Lee KH, Chen YL, Yeh SD, Hsiao M, Lin JT, Goan YG, Lu PJ: Microrna-330 acts as tumor suppressor and induces apoptosis of prostate cancer cells through e2f1-mediated suppression of akt phosphorylation. Oncogene 2009;28:3360-3370.

$>10$ Rambow F, Bechadergue A, Saintigny G, Morizot F, Mahe C, Larue L: Mir-330-5p targets tyrosinase and induces depigmentation. J Invest Dermatol 2014;134:2846-2849.

$>11$ Meng H, Wang K, Chen X, Guan X, Hu L, Xiong G, Li J, Bai Y: Microrna-330-3p functions as an oncogene in human esophageal cancer by targeting programmed cell death 4. Am J Cancer Res 2015;5:1062-1075.

12 Guan A, Wang H, Li X, Xie H, Wang R, Zhu Y, Li R: Mir-330-3p inhibits gastric cancer progression through targeting msi1. Am J Transl Res 2016;8:4802-4811.

13 Mesci A, Huang X, Taeb S, Jahangiri S, Kim Y, Fokas E, Bruce J, Leong HS, Liu SK: Targeting of ccbe1 by mir330-3p in human breast cancer promotes metastasis. Br J Cancer 2017;116:1350-1357.

14 Hu X, Feng Y, Sun L, Qu L, Sun C: Roles of microrna-330 and its target gene ing4 in the development of aggressive phenotype in hepatocellular carcinoma cells. Dig Dis Sci 2017;62:715-722.

15 Liu X, Shi H, Liu B, Li J, Liu Y, Yu B: Mir-330-3p controls cell proliferation by targeting early growth response 2 in non-small-cell lung cancer. Acta Biochim Biophys Sin (Shanghai) 2015;47:431-440. 


\section{Cellular Physiology Cell Physiol Biochem 2018;46:442-450 DOI: 10.1159/000488612
and Biochemistry \begin{tabular}{l}
$\begin{array}{l}\text { O 2018 The Author(s). Published by S. Karger AG, Basel } \\
\text { www.karger.com/cpb }\end{array}$ \\
\cline { 2 - 3 }
\end{tabular}

16 Qu S, Yao Y, Shang C, Xue Y, Ma J, Li Z, Liu Y: Microrna-330 is an oncogenic factor in glioblastoma cells by regulating sh3gl2 gene. PLoS One 2012;7:e46010.

17 Yao Y, Xue Y, Ma J, Shang C, Wang P, Liu L, Liu W, Li Z, Qu S, Liu Y: Mir-330-mediated regulation of sh3gl2 expression enhances malignant behaviors of glioblastoma stem cells by activating erk and pi3k/akt signaling pathways. PLoS One 2014;9:e95060.

18 Li Y, Zhu X, Xu W, Wang D, Yan J: Mir-330 regulates the proliferation of colorectal cancer cells by targeting cdc42. Biochem Biophys Res Commun 2013;431:560-565.

19 Mao Y, Chen H, Lin Y, Xu X, Hu Z, Zhu Y, Wu J, Zheng X, Xie L: Microrna-330 inhibits cell motility by downregulating sp1 in prostate cancer cells. Oncol Rep 2013;30:327-333.

-20 Shao Y, Geng Y, Gu W, Ning Z, Jiang J, Pei H: Prognostic role of high bmi-1 expression in asian and caucasian patients with solid tumors: A meta-analysis. Biomed Pharmacother 2014;68:969-977.

21 Silva J, Garcia JM, Pena C, Garcia V, Dominguez G, Suarez D, Camacho FI, Espinosa R, Provencio M, Espana P, Bonilla F: Implication of polycomb members bmi-1, mel-18, and hpc-2 in the regulation of p16ink4a, p14arf, h-tert, and c-myc expression in primary breast carcinomas. Clin Cancer Res 2006;12:6929-6936.

22 Siddique HR, Saleem M: Role of bmi1, a stem cell factor, in cancer recurrence and chemoresistance: Preclinical and clinical evidences. Stem Cells 2012;30:372-378. 